\title{
Cardioprotective Effects of Quercetin Against Ischemia-Reperfusion Injury Are Age-Dependent
}

\author{
M. BARTEKOVA ${ }^{1,2}$, J. RADOSINSKA $^{1,2}$, D. PANCZA $^{1}$, M. BARANCIK ${ }^{1}$, \\ T. RAVINGEROVA ${ }^{1}$
}

${ }^{1}$ Institute for Heart Research, Slovak Academy of Sciences, Bratislava, Slovak Republic, ${ }^{2}$ Institute of Physiology, Faculty of Medicine, Comenius University in Bratislava, Slovak Republic

Received June 1, 2016

Accepted June 15, 2016

\section{Summary}

Quercetin, a polyphenolic compound present in various types of food, has been shown to exert beneficial effects in different cardiac as well as non-cardiac ischemia/reperfusion (I/R) models in adult animals. However, there is no evidence about the effects of quercetin on I/R injury in non-mature animals, despite the fact that efficiency of some interventions against $I / R$ is agedependent. This study was aimed to investigate the effects of chronic quercetin treatment on I/R injury in juvenile and adult rat hearts. Juvenile (4-week-old) as well as adult (12-week-old) rats were treated with quercetin ( $20 \mathrm{mg} / \mathrm{kg} /$ day) for 4 weeks, hearts were excised and exposed to 25-min global ischemia followed by 40-min reperfusion. Functional parameters of hearts and occurrence of reperfusion arrhythmias were registered to assess the cardiac function. Our results have shown that quercetin improved post-ischemic recovery of LVDP, as well as recovery of markers of contraction and relaxation, $+(\mathrm{dP} / \mathrm{dt}) \max$ and $-(\mathrm{dP} / \mathrm{dt}) \max$, respectively, in juvenile hearts, but not in adult hearts. Quercetin had no impact on incidence as well as duration of reperfusion arrhythmias in animals of both ages. We conclude that the age of rats plays an important role in heart response to quercetin treatment in the particular dose and duration of the treatment. Therefore, the age of the treated subjects should be taken into consideration when choosing the dose of quercetin and duration of its application in prevention and/or treatment of cardiovascular diseases.

\section{Key words}

Quercetin • Heart • Ischemia-reperfusion • Age

\section{Corresponding author}

M. Bartekova, Institute for Heart Research, Slovak Academy of Sciences, Bratislava, Slovak Republic. E-mail: monika.bartekova@savba.sk

\section{Introduction}

Ischemia-reperfusion (I/R) injury of the heart belongs to leading causes of morbidity and mortality in developed countries. One of the major mechanisms participating on the development of subcellular defects in the heart due to I/R injury is oxidative stress (Dhalla et al. 2000). Numerous studies have shown that prevention and/or treatment with various types of antioxidants, such as vitamin E (Saleh and Saleh 2011, Dianat et al. 2014), $\mathrm{N}$-acetylcysteine, N-mercaptopropionylglycine (SainiChohan and Dhalla 2009), stobadine (Knezl et al. 1999, Brosková et al. 2013) as well as various natural plantderived antioxidant substances including flavonoids (Bartekova et al. 2010, Khandelwal et al. 2011), have a potential to increase the resistance of the heart to $I / R$ injury. Quercetin is a naturally occurring polyphenolic substance with proposed positive effects on cardiovascular system (CVS). Main natural sources of quercetin are various types of food such as vegetables, fruits or red wine (Hertog et al. 1996). This flavonoid possesses various biological activities including antioxidative, anti-apoptotic, anti-inflammatory, and oxygen radical-scavenging activities (Erden Inal and Kahraman 2000, Wu et al. 2014). Quercetin has been shown to induce several positive effects in CVS such as blood pressure lowering effects (Perez-Vizcaino et al. 2009, 
Larson et al. 2012) or protective effects on hearts exposed to I/R injury (Ikizler et al. 2007, Bartekova et al. 2010, 2015). It has been also documented that quercetin exerts protective effects in non-cardiac I/R models such as renal (Singh et al. 2004, Chen et al. 2014), brain (Yao et al. 2012, Lei et al. 2015) or liver ( $\mathrm{Su}$ et al. 2003, Tokyol et al. 2006) ischemia. It has been demonstrated that the efficiency of certain protective interventions against I/R injury may be age-dependent. Recently, it has been shown that the potency of ischemic preconditioning in isolated perfused rat hearts is age-dependent (Griecsova et al. 2015). In this respect, the knowledge about the efficiency of quercetin in the hearts of various age could be of potential interest and importance for its application in the prevention and treatment of $I / R$ injury. However, protective effects of quercetin on $\mathrm{I} / \mathrm{R}$ injury have been documented only in adults, there is no evidence on age-dependence of quercetin effects on I/R. Therefore, the aim of our present study was to compare the effects of prolonged treatment with quercetin in juvenile rat hearts and rat hearts isolated from adult rats.

\section{Material and Methods}

\section{Experimental model}

Juvenile (4-week-old, weighted 80-100 g) and adult (12-week-old, weighted 200-250 g) male Wistar rats were used in the experiment.

Animals were divided into 4 groups: adult controls (AC), adults treated with quercetin (AQ), juvenile controls (JC) and juvenile rats treated with quercetin (JQ). The number of animals was the same in each group $(n=6)$. The rats were housed in a room with controlled temperature $\left(22-24^{\circ} \mathrm{C}\right), 12 / 12$ light-dark cycle and were fed with regular pellet diet. All animal experiments were performed in accordance with the rules issued by the State Veterinary Administration of the Slovak Republic, project No. 241/08-221, and with the regulations of the Animal Research and Care Committee of Institute for Heart Research SAS. The groups AQ and JQ received quercetin in a dose of $20 \mathrm{mg} / \mathrm{kg} /$ day for 4 weeks. Quercetin (Sigma, USA) was administered to the rats in drinking water as described previously (Mézešová et al. 2010). Briefly, quercetin was dissolved in a small amount of ethanol and then dissolved in $0.1 \mathrm{~mol} \cdot \mathrm{l}^{-1}$ phosphate buffer, $\mathrm{pH} 6.0$ to keep maximal stability of quercetin in solution (previous experiments have shown maximal stability of quercetin at $\mathrm{pH} 6.0$ ) so that the final concentration of ethanol in drinking solution was $1 \%$ (vol./vol.). The control animals received $0.1 \mathrm{M}$ phosphate buffer, pH 6.0 with $1 \%$ ethanol as drinking solution. The weight of animals and the amount of water consumption were measured every day and the dose of quercetin was counted according to these data every day. This dose of quercetin, as well as the duration of treatment and mode of delivery, was chosen according to our preliminary experiments where this particular dose of quercetin blocked increase of blood pressure in juvenile spontaneously hypertensive rats and prevented development of hypertension (Barteková et al. 2008). After 4 weeks of treatment with quercetin, the animals were anesthetized and the hearts were excised and perfused according to Langendorff to test their resistance against I/R injury.

\section{Perfusion technique and determination of heart function}

After rats were anesthetized with thiopental (50 mg/kg, i.p.) and heparinized (500 IU, i.p.), the hearts were rapidly excised, placed in ice-cold perfusion buffer, cannulated via the aorta and placed on the Langendorff setup (ADInstruments, Germany) for perfusion at a constant perfusion pressure of $73 \mathrm{~mm} \mathrm{Hg}$ and temperature of $37^{\circ} \mathrm{C}$. Perfusion solution was a modified Krebs-Henseleit buffer gassed with $95 \% \mathrm{O}_{2}$ and $5 \%$ $\mathrm{CO}_{2}$ (pH 7.4) containing (in mmol/l): $\mathrm{NaCl} 118.0$; $\mathrm{KCl} 3.2 ; \mathrm{MgSO}_{4}$ 1.2; $\mathrm{NaHCO}_{3}$ 25.0; $\mathrm{KH}_{2} \mathrm{PO}_{4}$ 1.18; $\mathrm{CaCl}_{2}$ 2.5; glucose 7.0. This solution was filtered through the $5 \mu \mathrm{m}$ porosity filter to remove contaminants. An epicardial electrogram was registered by means of two stainless steel electrodes attached to the apex of the heart and aortic cannula. Left ventricular pressure was measured by means of a water-filled balloon inserted into the left ventricle via the left atrium (adjusted to obtain end-diastolic pressure of $1-5 \mathrm{~mm} \mathrm{Hg}$ ) and connected to a pressure transducer. Left ventricular developed pressure (LVDP, systolic minus diastolic pressure), maximal rates of pressure development and fall, +(dP/dt)max and $-(\mathrm{dP} / \mathrm{dt}) \max$, as the indexes of contraction and relaxation were used to assess cardiac function. Recovery of these parameters after ischemia/reperfusion was expressed as a percentage of pre-ischemic baseline values. Heart rate (calculated from EG) and coronary flow were measured during the whole experiment as well. Occurrence and duration of ventricular fibrillation as well as the incidence of ventricular tachycardia (VT), which was defined as a run of four or more consecutive ectopic beats and 
characterized by both the number of its episodes and its duration, were monitored to assess the reperfusion arrhythmias. Global ischemia was maintained for $25 \mathrm{~min}$, followed by a $40 \mathrm{~min}$ reperfusion. Functional parameters of hearts were measured during the whole reperfusion, reperfusion arrhythmias were monitored during the first $10 \mathrm{~min}$ of reperfusion.

\section{Statistical evaluations}

Data are presented as means \pm SEM. Statistical significance between two groups was tested by Student's unpaired $t$-test, the effects of quercetin were always compared to the corresponding control groups (JQ vs. JC, AQ vs. AC). Statistical significance of differences among all groups was analyzed by two-way ANOVA using the Holm-Sidak post-hoc test. Differences were considered significant at $\mathrm{p}<0.05$ in all the tests.

\section{Results}

Effect of quercetin on functional parameters of isolated hearts exposed to $I / R$

Our results have shown that 4 -week chronic treatment with quercetin had no effect on pre-ischemic values of functional parameters of hearts in juvenile as well as in adult rat hearts (Table 1). We have shown that quercetin treatment significantly improved post-ischemic recovery of functional parameters of isolated hearts in juvenile animals. This improvement was manifested by significantly improved recovery of $+(\mathrm{dP} / \mathrm{dt}) \max$ (45.92 $\pm 6.56 \%$ in JQ vs. $18.85 \pm 4.88 \%$ in $\mathrm{JC}, \mathrm{P}=0.016$ ) (Fig. 1A), $\quad-(\mathrm{dP} / \mathrm{dt}) \max \quad(60.92 \pm 8.57 \%$ in JQ vs. $27.13 \pm 8.92 \%$ in JC, $\mathrm{P}=0.04$ ) (Fig. 1B), as well as LVDP $(57.48 \pm 6.74 \%$ in JQ vs. $23.05 \pm 9.93 \%$ in $\mathrm{JC}, \mathrm{P}=0.031)$

(Fig. 1C) in the $40^{\text {th }}$ minute of reperfusion. In contrast to findings in juvenile hearts, quercetin had no effect on post-ischemic recovery of functional parameters in adult rat hearts $(25.3 \pm 8.23 \%$ in $\mathrm{AQ}$ vs. $27.86 \pm 9.28 \%$ in $\mathrm{AC}$, $\mathrm{P}=0.84$ for $+(\mathrm{dP} / \mathrm{dt}) \max ; 28.54 \pm 8.69 \%$ in $\mathrm{AQ}$ vs. $33.14 \pm 10.58 \%$ in $\mathrm{AC}, \quad \mathrm{P}=0.75$ for $-(\mathrm{dP} / \mathrm{dt}) \max$; $27.06 \pm 8.19 \%$ in $\mathrm{AQ}$ vs. $29.34 \pm 10.03 \%$ in $\mathrm{AC}, \mathrm{P}=0.86$ for LVDP) (Fig. 1A-C). Quercetin failed to prevent I/R-induced increase in end-diastolic pressure in both adult and juvenile hearts. However, the two-way ANOVA revealed the increase of end-diastolic pressure in the reperfusion to be age-dependent with lower I/R-induced increase in juvenile hearts (Fig. 1D). Finally, quercetin did not affect heart rate and coronary flow in all animals of both ages during whole experiment (data not shown).

\section{Effect of quercetin on reperfusion arrhythmias}

Occurrence and total duration of ventricular fibrillation as well as total number of episodes and total duration of ventricular tachycardia were monitored in the first $10 \mathrm{~min}$ of reperfusion to assess ischemia-induced reperfusion arrhythmias in all experimental groups of hearts. Our results have shown no occurrence of ventricular fibrillation in all hearts included in experiment (data not shown); however, we have detected ventricular tachycardia in all experimental groups. Quercetin failed to decrease the total number of episodes of ventricular tachycardia (Fig. 2A) as well as to decrease the total duration of ventricular tachycardia (Fig. 2B) in both juvenile and adult rat hearts when compared with corresponding controls. However, the two-way ANOVA revealed significant difference between total duration of ventricular tachycardia between juvenile and adult hearts, independently of the quercetin treatment with its longer total duration in adults (Fig. 2B).

Table 1. Pre-ischemic values of functional parameters of isolated hearts.

\begin{tabular}{lcccc}
\hline Group & JC & JQ & AC & AQ \\
\hline HR (beats/min) & $283 \pm 21$ & $265 \pm 25$ & $270 \pm 6$ & $249 \pm 11$ \\
$C F(\mathrm{ml} / \mathrm{min})$ & $6.12 \pm 0.36$ & $5.88 \pm 0.62$ & $7.36 \pm 0.40$ & $6.96 \pm 0.59$ \\
$L V D P(\mathrm{~mm} \mathrm{Hg})$ & $76.6 \pm 7.50$ & $83.72 \pm 4.54$ & $89.64 \pm 9.51$ & $89.52 \pm 8.94$ \\
$+(d P / d t) \max (\mathrm{mm} \mathrm{Hg} / \mathrm{s})$ & $3295 \pm 281$ & $3366 \pm 220$ & $3105 \pm 583$ & $3283 \pm 404$ \\
$-(d P / d t) \max (\mathrm{mm} \mathrm{Hg} / \mathrm{s})$ & $2054 \pm 214$ & $2125 \pm 146$ & $2079 \pm 290$ & $2179 \pm 258$ \\
\hline
\end{tabular}

JC - juvenile controls, JQ - juvenile treated with quercetin, AC - adult controls, AQ - adult treated with quercetin. 

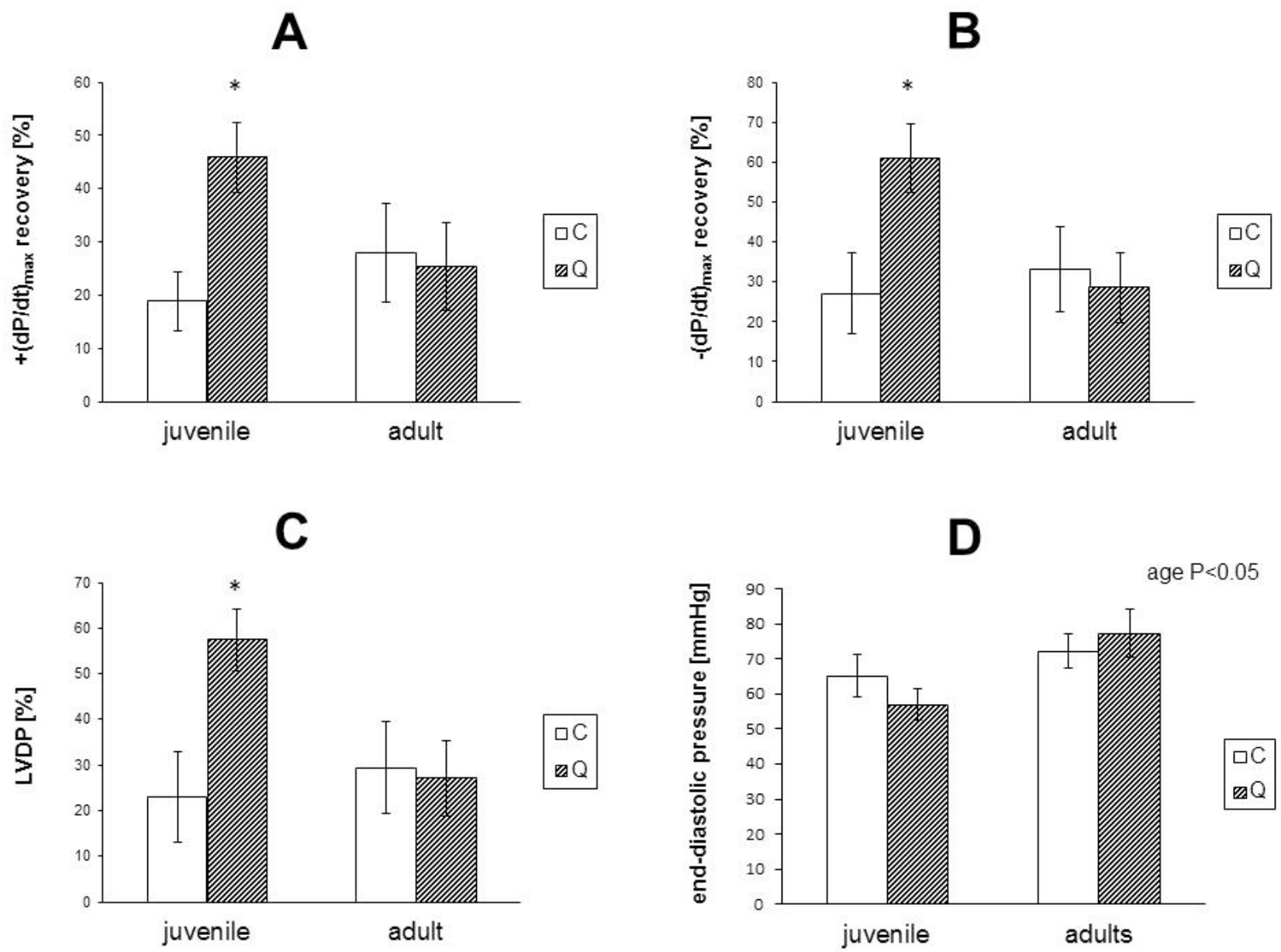

Fig. 1. Effects of quercetin on functional parameters of juvenile and adult rat hearts in the $40^{\text {th }}$ minute of post-ischemic reperfusion. (A) Post-ischemic recovery of the maximal rate of pressure development $+(\mathrm{dP} / \mathrm{dt}) \mathrm{max}$, (B) Post-ischemic recovery of the maximal rates of pressure fall $-(\mathrm{dP} / \mathrm{dt}) \max _{\text {, }}(\mathbf{C})$ Post-ischemic recovery of the left ventricular developed pressure LVDP, (D) Post-ischemic levels of the end-diastolic pressure. Functional parameters were determined after 25 min lasting global ischemia followed by a 40-min reperfusion. The recovery of parameters was expressed as a percentage of pre-ischemic baseline values, the levels of end-diastolic pressure are presented in $\mathrm{mmHg}$. Each bar represents mean $\pm \mathrm{SEM}$. $* \mathrm{P}<0.05$ vs. corresponding control.

A

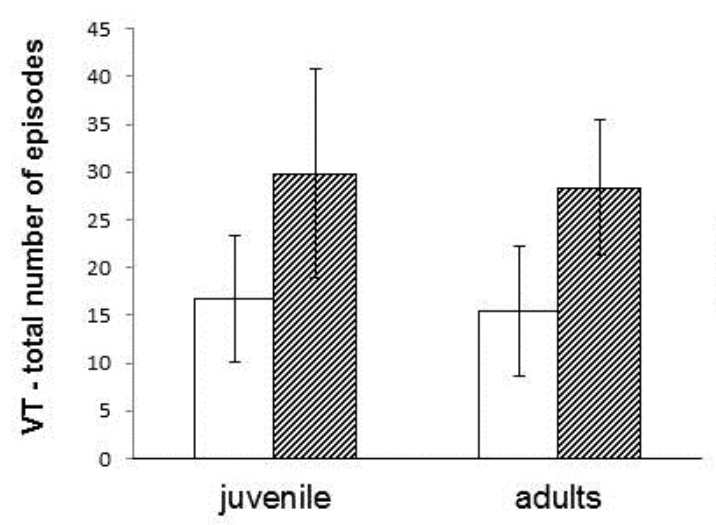

B

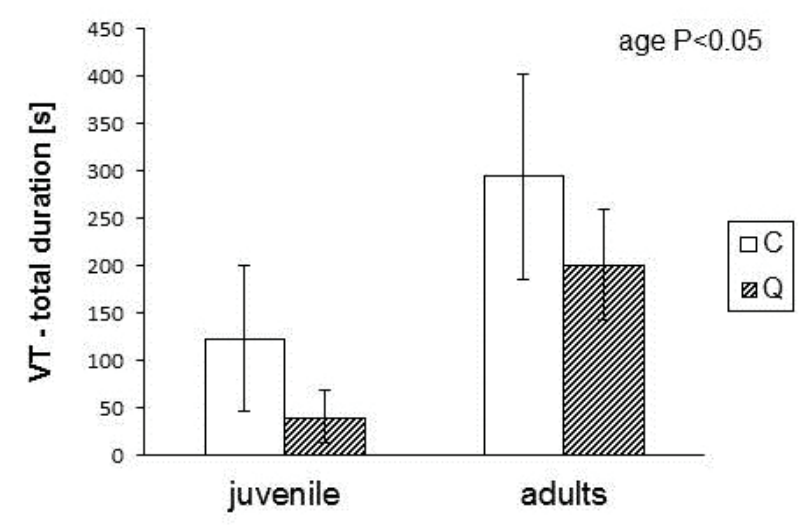

Fig. 2. Effects of quercetin on reperfusion arrhythmias in juvenile and adult rat hearts. (A) Total number of episodes of ventricular tachycardia, (B) Total duration of ventricular tachycardia. Arrhythmias were determined after 25 min lasting global ischemia during the first 10 min of reperfusion. Each bar represents mean \pm SEM. Statistical significance is revealed by two-way ANOVA. 


\section{Discussion}

In the present study, we have documented for the first time that cardioprotective effects of quercetin against I/R injury are age-dependent. We have shown that 4-week's chronic treatment of the rats with quercetin at the dose of $20 \mathrm{mg} / \mathrm{kg} /$ day led to significant improvement of post-ischemic recovery of functional parameters LVDP, +(dP/dt)max and - $(\mathrm{dP} / \mathrm{dt}) \max$ in Langendorffperfused juvenile rat hearts exposed to 25-min global ischemia and consequent 40-min reperfusion, while no protective effects were documented in adult hearts. On the other hand, quercetin failed to modify post-ischemic increase of end-diastolic pressure in hearts of both ages. Finally, our data have shown no effects of quercetin on total number of episodes and total duration of ventricular tachycardia during post-ischemic reperfusion in both juvenile and adult hearts.

It has been shown previously that age, as well as other co-morbidities, belongs to the important factors that may influence efficiency of preventive interventions against I/R injury (Ferdinandy et al. 2014, Griecsová et al. 2015). Quercetin has been shown to exert protective effects against $\mathrm{I} / \mathrm{R}$ injury after both acute and chronic administration (Ikizler et al. 2007, Barteková et al. 2010, Jin et al. 2012, Liu et al. 2014); however, its efficiency in relation to the age of the treated subject has not been studied yet. Here we have shown that cardioprotective effect of quercetin on post-ischemic recovery of functional parameters of isolated rat hearts is age-dependent with its better efficiency in young animals. This finding is in concordance with findings of Griecsova et al. (2015) where the authors have shown that efficiency of another cardioprotective intervention against $\mathrm{I} / \mathrm{R}$ injury, ischemic preconditioning, is also age-dependent, supporting the view that the age of the treated subject might be the determining factor for success in different interventions against $\mathrm{I} / \mathrm{R}$ injury.

It is surprising that our data have shown no protective effect of quercetin in adult hearts even if other authors have shown quercetin to be protective against I/R injury in adult hearts (Ikizler et al. 2007, Jin et al. 2012, Liu et al. 2014). However, their findings were obtained by using either higher doses of quercetin (Ikizler et al. 2007, Liu et al. 2014), or different duration of the treatment (Bartekova et al. 2015), or different mode of the quercetin delivery (Jin et al. 2012). It seems that not only the dose and the duration of the treatment, but also the mode of the drug delivery may play a crucial role in efficiency of quercetin against I/R injury. In concordance with this view are the findings of Carlstrom et al. (2007) showing that quercetin added to the feeding diet had no effect on the onset or the severity of cardiovascular complications that develop in spontaneously hypertensive rats, while the administration of quercetin via oral gavage lowered arterial blood pressure in these rats.

It has been shown previously that pretreatment with quercetin exerts antiarrhythmic effects in anesthetized rats exposed to $\mathrm{I} / \mathrm{R}$ when applied 2 min prior to reperfusion (Xiao et al. 1993) as well as in peroxynitrite-induced arrhythmias in isolated cardiac tissues and anesthetized animals (Soloviev et al. 2002). However, our data demonstrated no protective effect of quercetin on total number of episodes of ventricular tachycardia as well as on total duration of ventricular tachycardia in the rat hearts of both ages. The reason of this discrepancy may result from the different experimental models used as well as different dose and mode of quercetin delivery. On the other hand, our results have shown that increasing age of animals significantly increases total duration of ventricular tachycardia during post-ischemic reperfusion of isolated hearts, independently of quercetin treatment. These findings are in concordance with previous studies where the aging has been shown to be an important factor that increases susceptibility of hearts to reperfusion arrhythmias (Ledvényiová et al. 2013). Anyway, potential protective effects of quercetin on occurrence and severity of reperfusion arrhythmias remain the matter of doubt and should be studied intensively in the future.

Numerous mechanisms, including activation of PI3K/Akt pathway, increased activity of endogenous antioxidant systems, up-regulation of connexins (Bartekova et al. 2015), as well as attenuation of apoptosis via inhibition of JNK and p38 mitogenactivated protein kinase signaling pathways (Li et al. 2016) have been suggested to be involved in cardioprotective effects of quercetin against I/R injury. On the other hand, the molecular basis of age-dependency of quercetin efficiency against $\mathrm{I} / \mathrm{R}$ injury is not clear. Based on the literature we can speculate that the age-dependent level of activation of Akt kinase due to preventive interventions against I/R injury (Griecsova et al. 2015) might be one of the factors participating in the cardiopriotective effects of quercetin in the treatment of subjects of different ages. Unfortunately, our present study has not solved this question as the molecular mechanisms have not been studied. 


\section{Conclusions}

Our study demonstrated for the first time that cardioprotective effects of flavonoid quercetin against $I / R$ injury are age-dependent with its better effects on functional recovery in young animals. On the other hand, quercetin had no effect on total duration and total number of episodes of ventricular tachycardia in the hearts of both ages. We conclude that the age of treated subject might be one of the determining factors in efficiency of quercetin treatment against $\mathrm{I} / \mathrm{R}$ injury, and should be taken into consideration in quercetin application.

\section{Conflict of Interest}

There is no conflict of interest.

\section{Acknowledgements}

This study was supported by grants VEGA SR no. 2/0061/16, 2/0108/15 and 2/0201/15, APVV-0348-12 and APVV-0102-11.

\section{References}

BARTEKOVÁ M, DITTE Z, SULOVÁ Z, KRIŽANOVÁ O, ŠÍROVÁ M, PECHÁŇOVÁ O, PANCZA D, BREIER A: The effect of quercetin on physiological and biochemical parameters of normotensive and hypertensive rats. Physiol Res 57: 9P, 2008.

BARTEKOVÁ M, ČARNICKÁ S, PANCZA D, ONDREJČÁKOVÁ M, BREIER A, RAVINGEROVÁ T: Acute treatment with polyphenol quercetin improves postischemic recovery of isolated perfused rat hearts after global ischemia. Can J Physiol Pharmacol 88: 465-471, 2010.

BARTEKOVÁ M, ŠIMONČÍKOVÁ P, FOGARASSYOVÁ M, IVANOVÁ M, OKRUHLICOVÁ L', TRIBULOVÁ N, DOVINOVÁ I, BARANČÍK M: Quercetin improves postischemic recovery of heart function in doxorubicintreated rats and prevents doxorubicin-induced matrix metalloproteinase-2 activation and apoptosis induction. Int J Mol Sci 16: 8168-8185, 2015.

BROSKOVA Z, KYSELOVA Z, KNEZL V: Ischemia-reperfusion injury of the isolated diabetic rat heart: effect of the antioxidant stobadine. Gen Physiol Biophys 32: 285-292, 2013.

CARLSTROM J, SYMONS JD, WU TC, BRUNO RS, LITWIN SE, JALILI T: A quercetin supplemented diet does not prevent cardiovascular complications in spontaneously hypertensive rats. J Nutr 137: 628-633, 2007.

CHEN BL, WANG LT, HUANG KH, WANG CC, CHIANG CK, LIU SH: Quercetin attenuates renal ischemia/reperfusion injury via an activation of AMP-activated protein kinase-regulated autophagy pathway. J Nutr Biochem 25: 1226-1234, 2014.

DHALLA NS, ELMOSELHI AB, HATA T, MAKINO N: Status of myocardial antioxidants in ischemia-reperfusion injury. Cardiovasc Res 47: 446-456, 2000.

DIANAT M, ESMAEILIZADEH M, BADAVI M, SAMARBAFZADEH A, NAGHIZADEH B: Protective effects of crocin on hemodynamic parameters and infarct size in comparison with vitamin $\mathrm{E}$ after ischemia reperfusion in isolated rat hearts. Planta Med 80: 393-398, 2014.

ERDEN INAL M, KAHRAMAN A: The protective effect of flavonol quercetin against ultraviolet a induced oxidative stress in rats. Toxicology 154: 21-29, 2000.

FERDINANDY P, HAUSENLOY DJ, HEUSCH G, BAXTER GF, SCHULZ R: Interaction of risk factors, comorbidities, and comedications with ischemia/reperfusion injury and cardioprotection by preconditioning, postconditioning, and remote conditioning. Pharmacol Rev 66: 1142-1174, 2014.

GRIECSOVÁ L, FARKAŠOVÁ V, GÁBLOVSKÝ I, KHANDELWAL VK, BERNÁTOVÁ I, TATARKOVÁ Z, KAPLAN P, RAVINGEROVÁ T: Effect of maturation on the resistance of rat hearts against ischemia. Study of potential molecular mechanisms. Physiol Res 64 (Suppl 5): S685-S696, 2015.

HERTOG MG, BUENO-DE-MESQUITA HB, FEHILY AM, SWEETNAM PM, ELWOOD PC, KROMHOUT D: Fruit and vegetable consumption and cancer mortality in the Caerphilly Study. Cancer Epidemiol Biomarkers Prev 5: 673-677, 1996.

IKIZLER M, ERKASAP N, DERNEK S, KURAL T, KAYGISIZ Z: Dietary polyphenol quercetin protects rat hearts during reperfusion: enhanced antioxidant capacity with chronic treatment. Anadolu Kardiyol Derg 7: 404-410, 2007. 
JIN HB, YANG YB, SONG YL, ZHANG YC, LI YR: Protective roles of quercetin in acute myocardial ischemia and reperfusion injury in rats. Mol Biol Rep 39: 11005-11009, 2012.

KHANDELWAL VK, BALARAMAN R, PANCZA D, RAVINGEROVÁ T: Hemidesmus indicus and Hibiscus rosasinensis affect ischemia reperfusion injury in isolated rat hearts. Evid Based Complement Alternat Med 2011: 802937, 2011.

KNEZL V, SOTNÍKOVÁ R, OKRUHLICOVÁ L, NAVAROVÁ J: Effect of stobadine on cardiac injury induced by ischemia and reperfusion. Life Sci 65: 1931-1933, 1999.

LARSON AJ, SYMONS JD, JALILI T: Therapeutic potential of quercetin to decrease blood pressure: review of efficacy and mechanisms. Adv Nutr 3: 39-46, 2012.

LEDVÉNYIOVÁ V, PANCZA D, MATEJÍKOVÁ J, FERKO M, BERNÁTOVÁ I, RAVINGEROVÁ T: Impact of age and sex on response to ischemic preconditioning in the rat heart: differential role of the PI3K-AKT pathway. Can J Physiol Pharmacol 91: 640-647, 2013.

LEI X, CHAO H, ZHANG Z, LV J, LI S, WEI H, XUE R, LI F, LI Z: Neuroprotective effects of quercetin in a mouse model of brain ischemic/reperfusion injury via anti-apoptotic mechanisms based on the Akt pathway. Mol Med Rep 12: 3688-3696, 2015.

LI C, WANG T, ZHANG C, XUAN J, SU C, WANG Y: Quercetin attenuates cardiomyocyte apoptosis via inhibition of JNK and p38 mitogen-activated protein kinase signaling pathways. Gene 577: 275-280, 2016.

LIU H, GUO X, CHU Y, LU S: Heart protective effects and mechanism of quercetin preconditioning on antimyocardial ischemia reperfusion (IR) injuries in rats. Gene 545: 149-155, 2014.

MEZESOVA L, BARTEKOVA M, JAVORKOVA V, VLKOVICOVA J, BREIER A, VRBJAR N: Effect of quercetin on kinetic properties of renal Na,K-ATPase in normotensive and hypertensive rats. $J$ Physiol Pharmacol 61: 593-598, 2010.

PEREZ-VIZCAINO F, DUARTE J, JIMENEZ R, SANTOS-BUELGA C, OSUNA A: Antihypertensive effects of the flavonoid quercetin. Pharmacol Rep 61: 67-75, 2009.

SAINI-CHOHAN HK, DHALLA NS: Attenuation of ischemia-reperfusion-induced alterations in intracellular $\mathrm{Ca}^{2+}$ in cardiomyocytes from hearts treated with N-acetylcysteine and N-mercaptopropionylglycine. Can J Physiol Pharmacol 87: 1110-1119, 2009.

SALEH NK, SALEH HA: Protective effects of vitamin E against myocardial ischemia/reperfusion injury in rats. Saudi Med J 31: 142-147, 2010.

SINGH D, CHANDER V, CHOPRA K: The effect of quercetin, a bioflavonoid on ischemia/reperfusion induced renal injury in rats. Arch Med Res 35: 484-494, 2004.

SOLOVIEV A, STEFANOV A, PARSHIKOV A, KHROMOV A, MOIBENKO A, KVOTCHINA L, BALAVOINE G, GELETII Y: Arrhythmogenic peroxynitrite-induced alterations in mammalian heart contractility and its prevention with quercetin-filled liposomes. Cardiovasc Toxicol 2: 129-139, 2002.

SU JF, GUO CJ, WEI JY, YANG JJ, JIANG YG, LI YF: Protection against hepatic ischemia-reperfusion injury in rats by oral pretreatment with quercetin. Biomed Environ Sci 16: 1-8, 2003.

TOKYOL C, YILMAZ S, KAHRAMAN A, CAKAR H, POLAT C: The effects of desferrioxamine and quercetin on liver injury induced by hepatic ischaemia-reperfusion in rats. Acta Chir Belg 106: 68-72, 2006.

WU J, XU X, LI Y, KOU J, HUANG F, LIU B, LIU K: Quercetin, luteolin and epigallocatechin gallate alleviate TXNIP and NLRP3-mediated inflammation and apoptosis with regulation of AMPK in endothelial cells. Eur $J$ Pharmacol 745: 59-68, 2014.

XIAO D, GU ZL, QIAN ZN: Effects of quercetin on platelet and reperfusion-induced arrhythmias in rats. Zhongguo Yao Li Xue Bao 14: 505-508, 1993.

YAO RQ, QI DS, YU HL, LIU J, YANG LH, WU XX: Quercetin attenuates cell apoptosis in focal cerebral ischemia rat brain via activation of BDNF-TrkB-PI3K/Akt signaling pathway. Neurochem Res 37: 2777-2786, 2012. 